

\title{
Des/ legitimación de las memorias históricas: Valoración en discursos pedagógicos intermodales de enseñanza básica chilena
}

\section{De/ legitimation of historical memories: Appraisal in intermodal pedagogical discourse of Chilean primary education}

\section{Teresa Oteíza}

PONTIFICIA UNIVERSIDAd CATÓLICA DE ChILE

CHILE

moteizas@uc.cl

\author{
Claudio Pinuer \\ UNIVERSIDAD DE CONCEPCIÓN \\ cpinuer@udec.cl
}

Recibido: 06/XI/2015 / Aceptado: 07/VI/2016

\section{Resumen}

En este artículo se analiza el componente valorativo intermodal incorporado en la representación de la violación a los derechos humanos cometida por la dictadura de Augusto Pinochet (1973-1990) en textos escolares de Historia. El estudio examina manuales escolares de Historia de sexto año de la educación básica chilena, licitados por el Ministerio de Educación del país. Se investiga la expresión de valoración inscrita y evocada en su configuración multimodal, específicamente en la integración entre las imágenes, sus epígrafes y el cuerpo de texto. Para acceder a la significación valorativa expresada bimodalmente, se integran el modelo de VALORACIÓN (Martin \& White, 2005) y la propuesta funcional de análisis intersemiótico elaborada principalmente por Kress y van Leeuwen (2006) y Painter, Martin y Unsworth (2013). Los resultados más importantes señalan que los espacios semióticos construidos en los textos escolares de Historia representan la violación a los derechos humanos como recurso de conocimiento histórico, con baja presencia de actores humanos, alta prominencia de la circunstancialización de la represión y con escasa reflexión en torno a los procesos que ocasionaron la violencia de Estado en el país. La unidad 'fotografía + epígrafe' funciona como fuente primaria que construye un discurso objetivado que privilegia los ritos de denuncia y de reparación social.

Palabras Clave: Modelo de valoración, multimodalidad, memorias históricas, violación a los derechos humanos, manuales escolares de Historia. 


\begin{abstract}
This article analyzes the valuative intermodal component that is incorporated in the representation of human rights violations committed by Augusto Pinochet's dictatorship (1973-1990) in History textbooks. The study examines sixth grade Chilean History textbooks that have been selected by the Ministry of Education. We investigate the codification of inscribed and evoked valuation in its multimodal configuration, specifically in the integration between images, their captions and the body of the text. In order to understand the valuative meaning expressed in a bimodal manner, we integrate the APPRAISAL framework (Martin \& White, 2005) and the proposal for a multimodal analysis elaborated mainly by Kress and van Leeuwen (2006) and Painter, Martin and Unsworth (2013). Our analyses show that the semiotic spaces built in the History textbooks represent human rights violations as a resource of historical knowledge, with low presence of human beings, high prominence of circumstatialization of the repression, and limited reflection on the processes that caused the state violence in the country. The unit 'photograph + caption' functions as a primary source that construes an objectified discourse that privileges the rituals of denunciation and social restoration.
\end{abstract}

Key Words: Appraisal framework, multimodality, historical memories, human rights violations, History textbooks.

\title{
INTRODUCCIÓN
}

Este artículo presenta el análisis discursivo intermodal de la transmisión de las memorias de la violación a los derechos humanos y de represión política cometidos durante la dictadura de Augusto Pinochet (1973-1990) y su recontextualización en textos escolares de historia oficiales de la enseñanza primaria en Chile (2005-2013). El estudio considera que la construcción discursiva de la significación histórica puede analizarse, en parte, a través del examen de prosodias valorativas intermodales (verbalvisual) de actores, eventos y procesos históricos como un procedimiento de decolocación y re-colocación que implica necesariamente selección, exclusión y resemiotización (Bernstein, 2000).

Precisamente sobre la base de la configuración del eje actoral y procesual, se aborda la plasmación de valoración bimodal como parte de la reinterpretación y resignificación desarrolladas particularmente en documentos oficiales de derechos humanos: Informe de la Comisión Nacional de Verdad y Reconciliación (Informe Rettig) e Informe de la Comisión Nacional sobre Prisión Política y Tortura (Informe Valech). Los textos académicos y documentos oficiales son el material documental básico para elaborar los manuales escolares de historia licitados por el gobierno, cuyo sello común es su manifiesta articulación con las iniciativas y políticas del Estado dirigidas al restablecimiento de la verdad, justicia, reparación y memoria, las cuales se han caracterizado por favorecer la reconciliación nacional, la despolitización de la memoria y la superación del conflicto. 
Este estudio de las des/legitimaciones de las memorias históricas y su recontextualización pedagógica se realiza desde los estudios multimodales en conjunto con categorías del modelo de valoración (Martin \& White, 2005), con el objetivo de explicar cómo se construye la orientación de los puntos de vista en ambos modos semióticos e intersemióticamente (Kress \& van Leeuwen, 2006; Painter, Martin \& Unsworth, 2013). En este artículo nos centramos puntualmente en el análisis de las fotografías y de sus respectivos epígrafes, los cuales son parte de las fuentes primarias incorporadas como evidencia en las explicaciones históricas construidas en el discurso.

En particular, este trabajo se propone responder de manera más específica por: (a) las maneras en que el pasado reciente de violación a los D.D.H.H. en Chile se construye intermodalmente en estos discursos pedagógicos; (b) el rol de los modos visuales, en particular de las fotografías consideradas como fuentes primarias, en la construcción de la evidencia histórica y (c) la integración intermodal de significados de la unidad 'fotografía+epígrafe' y su potencial valorativo en la construcción de significación histórica. Este artículo es parte de una investigación mayor que tiene como propósito contribuir al conocimiento de la transmisión de la memoria histórica a niños y jóvenes chilenos sobre el pasado reciente nacional de la violación a los derechos humanos (1973-1990) y que incluye tanto el análisis de textos escolares de historia para enseñanza básica y media, la interacción en aula de ambos niveles y entrevistas a estudiantes y a los profesores filmados en su interacción en aula de clases de historia.

\section{Fundamentos teóricos}

La dificultad de historizar eventos conflictivos recientes, unido al hecho de que la memoria histórica de una sociedad constituye una realidad subjetiva y cambiante que transforma y determina las interpretaciones del presente y del futuro, ha sido ampliamente documentada por historiadores y analistas del discurso interesados en temas de memoria y transmisión (Wertsch, 2002; Jelin, 2002, 2007; Ricoeur, 2010; Wodak, 2011; Stern, 2013; Oteíza, 2014; Achugar, Fernández \& Morales, 2014). Las memorias son consideradas formas de acción mediadas por herramientas culturales, lo que ha implicado, en el caso chileno, la legitimación y deslegitimación de los discursos del pasado reciente que circulan en la sociedad como 'memorias emblemáticas' y 'contra memorias' (Stern, 2013).

En relación a la transmisión de la memoria, nos interesa explorar particularmente la manera en que se incluyen en los textos escolares los monumentos y las acciones conmemorativas o las acciones rituales que van construyendo y modificando el sentido del pasado que se recuerda. Toda conmemoración oficial o de contramemoria implica una forma de ritualidad social organizada y constituye un acto simbólico realizado por sujetos que conmemoran, teniendo presente las memorias oficiales y las contramemorias. Así, un monumento es considerado por Jelin y Langland (2003) 
como 'un vehículo de la memoria' que, como marca territorial, está abierto al trabajo de la acción colectiva, política y simbólica de diferentes sectores de la sociedad. En el sentido anterior, un monumento es:

"en tanto materialización de la memoria uno de los campos de batalla en
los que diferentes sujetos combaten por la construcción de su proyecto
en función de sus particulares memorias y contramemorias" (Jelin \&
Langland, 2003: 4).

En resumen, los monumentos, como objetivación de la memoria y las acciones conmemorativas, comparten las siguientes características: (a) constituyen homenajes a las víctimas, a su compromiso político y su muerte trágica; (b) son fuente de transmisión de la memoria al resto de la sociedad, especialmente a las nuevas generaciones; y c) son lugares físicos de la memoria y lugares de enunciación de la memoria, por parte de los sujetos que le dan sentido al lugar (Nora, 1989; Jelin, 2002; Achugar, 2003; Piper, Fernández-Droguett \& Iñiguez-Rueda, 2013).

\subsection{Los discursos de la historia y la construcción de la evidencia}

Una de las dimensiones clave de todo discurso histórico - sin importar el tipo de género que constituya- es la causalidad, entendida como la representación discursiva de hechos, motivaciones, condiciones propiciatorias, antecedentes y factores implicados en una explicación histórica. La segunda dimensión fundamental es la tempo-espacialidad, dado que toda explicación histórica implica un tiempo y un espacio en los que sucedieron los hechos. La representación del tiempo y del espacio puede ser directa o simbólica, la primera sitúa los hechos en el tiempo y situación concretas, en tanto que la interpretación simbólica plasma la construcción temporal y espacial de los hechos desde determinados posicionamientos ideológicos (Lechner, 2006; Oteíza \& Pinuer, 2012, 2013).

Finalmente, la dimensión de evidencialidad se refiere al tipo de fuentes incorporadas en el discurso como documentos primarios o secundarios. En el trabajo historiográfico, el/la historiador/a selecciona la información contenida en las fuentes para la elaboración de la evidencia, con la cual construye una determinada significación histórica (Oteíza, 2014). Las tres dimensiones previamente descritas se actualizan en el discurso histórico mediante la representación de actores históricos individuales o colectivos (eje actoral) involucrados en eventos y procesos (eje procesual) ocurridos en situaciones históricas determinadas. Asimismo, estas dimensiones se construyen, dependiendo del tipo de historia desarrollada (política, económica, social u otra), con la ayuda de tecnicismos empleados en otras disciplinas y que constituyen, en parte, la tecnicalidad del discurso de la historia. 


\subsection{Recontextualización de la historia en textos escolares y construcción de la evidencia visual}

Los textos escolares en tanto instrumentos oficiales de difusión de las memorias colectivas, permiten explorar los posicionamientos ideológicos aceptados por una sociedad en relación a temas sensibles como el reconocimiento de la represión política de un período determinado. Los textos escolares "presentan un saber autorizado que ha recontextualizado los discursos históricos disciplinares en los que es posible evidenciar los consensos sociales y políticos sobre el pasado reciente nacional" (Oteíza, 2014: 113), que redundan en una especie de 'polifonía restringida' de explicaciones históricas unificadas y naturalizadas (Oteíza, 2011).

Las relaciones de intertextualidad son parte de la construcción de la memoria colectiva/emblemática y de la llamada 'historia analítica' (Wertsch, 2002) que sirve de base para elaborar el contexto histórico o político que acompañan a los informes oficiales, tal como ocurre en el Informe Rettig (1991) e Informes Valech (2004, 2011). Si bien ya se cuenta con un amplio número de estudios acerca de la construcción discursiva de los textos escolares de historia en Latinoamérica y en otras partes del mundo, el análisis de su composición intermodal (verbal y visual) es más escasa y solo ha adquirido notoriedad en los últimos años gracias, por ejemplo, a los trabajos de Morales y Lischinky (2008) en España; Derewianka y Coffin (2008) en Australia; Borges (2011) en Brasil; Zullo (2014) en Argentina; Oteíza (2006, 2009), Manghi (2013a, 2013b) y Manghi y Badillo (2015) para los textos escolares de historia chilenos.

De esta manera, en el contexto latinoamericano podemos destacar los estudios de Manghi (2013a, 2013b), quien desde una perspectiva de una semiótica social aborda el estudio de los materiales pedagógicos multimodales utilizados en clases de historia y de biología. Como parte de su estudio Manghi (2013a), considera el análisis de las fotografías que se incluyen en los textos escolares de historia y subraya su estructura narrativa y el papel como artefactos semióticos de veracidad de una época histórica. Por su parte, y siguiendo la misma línea teórica de una semiótica social, Borges (2011), analiza la Revolución Paulista brasileña desde su representación en los textos de historia, con el objetivo de identificar las marcas ideológicas que construyen multimodalmente estos textos. Asimismo, Zullo (2014), para el contexto argentino, analiza las representaciones sociales del último golpe de estado, y cómo estas son recontextualizadas en el material digital producido por el Ministerio de Educación para su circulación en las escuelas primarias del país.

Hemos mencionado que la evidencialidad es una dimensión esencial de todo discurso histórico, dado que la construcción de las cadenas causales precisa fundamentarse en hechos. Esto hace imprescindible el trabajo con fuentes primarias (archivos de diferente naturaleza, testimonios, entre otros), en las cuales el historiador selecciona información para elaborar la evidencia que sustente su argumentación 
histórica. Así, por ejemplo, las fotografías pueden utilizarse como testimonios del pasado, como documentos y como fuentes portadoras de información. Estas son particularmente importantes para nuestro análisis, considerando que del total de imágenes que se incluyen en los textos escolares analizados, sobre el $90 \%$ son fotografías, lo que implica una clara preferencia por este tipo de modo visual. En los textos escolares se produce una recontextualización de las fotografías, ya que no fueron tomadas para servir en este medio ni cumplir una función pedagógica.

Desde un enfoque sociosemiótico de la iconografía, las fotografías como íconos complejos construidos culturalmente no pueden interpretarse como elementos transparentes, inocentes y realistas (Kress \& van Leeuwen, 2006; Augustowsky, Massarini \& Tabakman, 2011). Las fotografías tienen la particularidad de tener un carácter de 'evidencia' y representar una 'orientación naturalista del código', llevando implícito un carácter de 'verdad' que se combina en el texto escolar con el 'régimen de creencia' (Kress \& van Leeuwen, 2006). Sin embargo, es necesario hacer notar que el objeto fotografiado tiene que haber estado en un lugar y momento puntual; de esa manera, la fotografía constituye una evidencia que puede ser empleada en la construcción de las explicaciones históricas.

Se comprende, entonces, que los contextos de interacción con las imágenes sean fundamentales, pues tendemos a mirarlas con expectativas y propósitos específicos. No podemos perder de vista que las imágenes se refieren al pasado reciente del país y, como plantea Achugar (2008), los estudiantes que interactúan con ellas traen consigo experiencias previas, de tal forma que lo observado es influido por evaluaciones morales y afectivas asociadas a la experiencia de recordar. Achugar (2008) pone de relieve la relación producida entre quien recuerda y lo recordado, lo que debe influir en cómo nos acercamos a las imágenes que son parte del pasado reciente nacional, aún cuando se trate de niños y niñas que no vivieron directamente la represión política.

Las imágenes se repiten entre los textos escolares debido, en parte, a la disponibilidad de los bancos de imágenes de las editoriales que producen textos escolares. La inclusión de las mismas imágenes en diferentes textos escolares producen significados intertextuales que se construyen como evidencias 'oficiales' del pasado o como dispositivos pedagógicos por estar incorporadas en estos textos de estudio. Las imágenes están conectadas a los intereses de las instituciones sociales en las que han sido producidas, puestas en circulación y leídas y, desde esa óptica, obedecen al quehacer de políticas públicas que operan a través de la industria editorial.

Finalmente y, en relación al peso simbólico de ciertas imágenes incorporadas en los textos escolares del corpus, en este trabajo incorporamos en una aproximación inicial la noción de 'ícono empático' (bondicon) propuesta por Martin (2008). Este concepto se refiere a los lazos afectivos e ideológicos que alinean a la gente en torno a valores e ideales comunitarios. De acuerdo con Martin (2008), el proceso de iconización es un 
fenómeno a través del cual estos 'íconos empáticos' acumulan valor en una comunidad.

\section{Marco metodológico}

\subsection{Corpus}

El corpus del estudio está compuesto por seis textos escolares de historia para sexto básico editados entre los años 2005 y 2013. La importancia de estos textos, es que fueron publicados con posterioridad a la difusión de los informes oficiales sobre violación a los derechos humanos cometidos durante la dictadura de A. Pinochet (1973-1990), el Informe Rettig (1991) y el Informe Valech (2004). Asimismo, estos textos corresponden a los últimos libros oficiales licitados por parte del Ministerio de Educación en los diez últimos años, con excepción del texto para sexto básico de la Editorial Arrayán 2005-2006. El número de textos oficiales se reduce a cinco, debido a que varios de los ejemplares disponibles son reimpresiones.

Cabe destacar que los textos escolares son considerados macrogéneros, lo cual se traduce en la presencia de variados géneros, destacando el recuento y el informe histórico, privilegiados en el presente estudio y en otros análisis desarrollados por Oteíza $(2006,2009)$ en textos escolares de historia de sexto año de enseñanza media editados con anterioridad a la primera publicación del Informe Valech, esto es, entre 1993 y 2003. Una explicitación completa del corpus se presenta en la Tabla 1:

Tabla 1. Corpus de Textos Escolares de Historia y de Documentos oficiales sobre violación a los DDHH en Chile.

\begin{tabular}{|l|l|}
\hline Corpus de referencia: \\
\hline $\begin{array}{l}\text { Informe de la Comisión Nacional de Verdad y } \\
\text { Reconciliación (Informe Rettig), 1991. }\end{array}$ & Comisión multidisciplinaria \\
\hline $\begin{array}{l}\text { Informe de la Comisión Nacional sobre Prisión Política } \\
\text { y Tortura (Informe Valech), 2004, 2011. }\end{array}$ & Comisión multidisciplinaria \\
\hline Corpus de textos escolares de primaria: & \\
\hline $\begin{array}{l}\text { Textos escolares de historia, sexto año básico } \\
\text { (Publicados entre 2005-2013) }\end{array}$ & $\begin{array}{l}\text { Ministerio de Educación de Chile. } \\
\text { (Editoriales: Santillana, MN, }\end{array}$ \\
& ZIGZAG) \\
[Arrayán, 2005-2006] \\
\hline
\end{tabular}

\subsection{Sistema de VALORACIÓN y análisis intermodal de procesos históricos}

Dado que el sistema de la valoración opera a nivel discursivo, este permite dar cuenta de la representación de actores sociales y eventos y procesos históricos. El modelo de valoración se organiza en los subsistemas semánticos de actitud, gradación y compromiso, los cuales posibilitan respectivamente el análisis de la actitud o de los posicionamientos, la gradación de la actitud y la identificación y clasificación de la 
fuente $\mathrm{u}$ origen de las valoraciones expresadas discursivamente. Estos subsistemas son abordados desde una perspectiva intermodal, con el objeto de acceder a las maneras en que se construye la dimensión de evidencialidad histórica en los textos de estudio seleccionados.

Como procedimiento metodológico se analizó de manera separada todo el texto verbal del corpus desde el sistema de valoración y, en una segunda fase, se analizaron las imágenes según los criterios que serán expuestos a continuación. Una tercera fase analítica consistió en explorar, desde una perspectiva intermodal, el significado que tanto la imagen como el texto verbal construyen en conjunto. Para efectos de este artículo, se nos centraremos de modo particular en el análisis de la unidad 'fotografía+epígrafe'.

A continuación, presentamos brevemente la organización metafuncional del análisis sociosemiótico propuesto por Halliday y desarrollado por Kress y van Leeuwen (2006) y Painter et al. (2013) para el estudio de las imágenes. Esta organización trinocular del lenguaje -en macrosignificados ideacionales, interpersonales y textuales- son elaborados por Kress y van Leeuwen (2006) para dar cuenta de una gramática del diseño visual en los significados: representacional representación de los eventos, participantes y circunstancias-, interaccional -relación entre imagen y observador y codificación de los posicionamientos ideológicos- y composicional -disposición y diseño de las imágenes en los textos. A continuación, en la Figura 1, se presenta mediante una red sistémica la articulación de las categorías consideradas para el análisis representacional de las imágenes: ${ }^{1}$

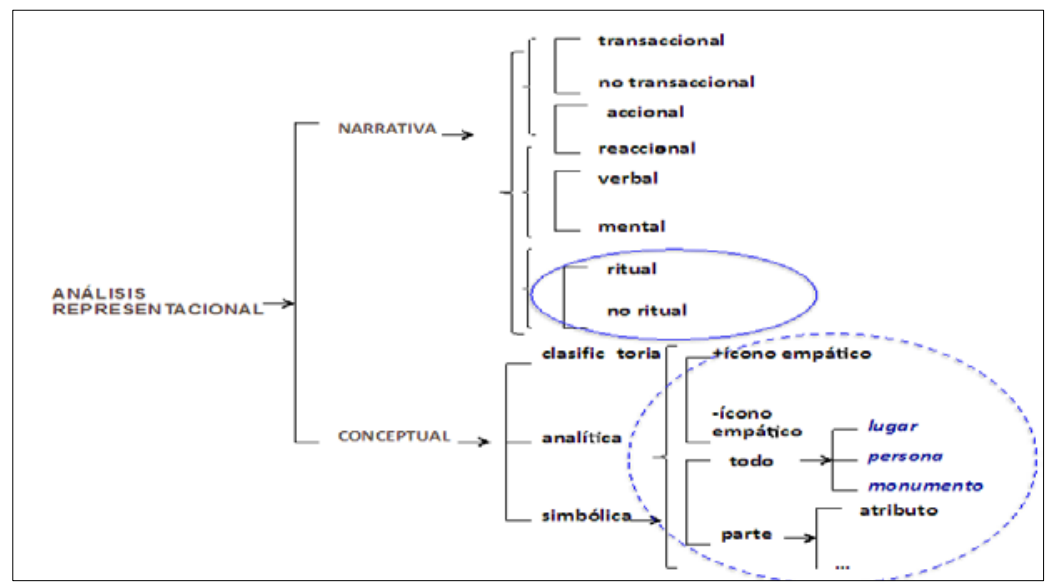

Figura 1. Análisis Representacional de las imágenes (Kress \&van Leeuwen (2006), con adaptación de autores, correspondiente a lo encerrado en elipsis).

En esta red sistémica de la Figura 1 se ofrece la versión original propuesta por Kress y van Leeuwen (2006) para el análisis representacional de las imágenes y en la cual se incluye una elaboración propia destinada a interpretar las categorías 
ideacionales fundamentales para el estudio de nuestro corpus. De esta forma, las categorías de 'ritual' y 'no ritual' dan cuenta de imágenes narrativas en las que existen o no presencia de seres humanos en una acción conmemorativa o de homenaje a las víctimas que sufrieron violación a sus derechos humanos. Estos actos son parte del proceso de transmisión de la memoria al resto de la sociedad y a las nuevas generaciones. Asimismo, la incorporación del concepto de 'ícono empático’ permite captar una especificidad de las imágenes simbólicas que incluyen elementos visuales que logran generar una empatía afectiva reconocida por toda una comunidad, como es el caso de las fotografías en línea de los rostros de detenidos-desaparecidos o la fotografía completa de un familiar en una manifestación que denuncia la falta de justicia. Este 'ícono empático' puede ser un atributo simbólico inserto en una imagen o puede estar constituido por la imagen como un todo.

En la Figura 2 se presentan las categorías empleadas para el análisis composicional, a través de una adaptación del diseño original de Kress y van Leeuwen (2006), propuesta por Painter et al. (2013) para el análisis de los libros álbum. A esta red hemos añadido algunas categorías para la integración intermodal, funcionalizadas al análisis de los textos escolares de historia y, particularmente, a la unidad 'fotografía+epígrafe' que exploramos con más detalle en este trabajo:

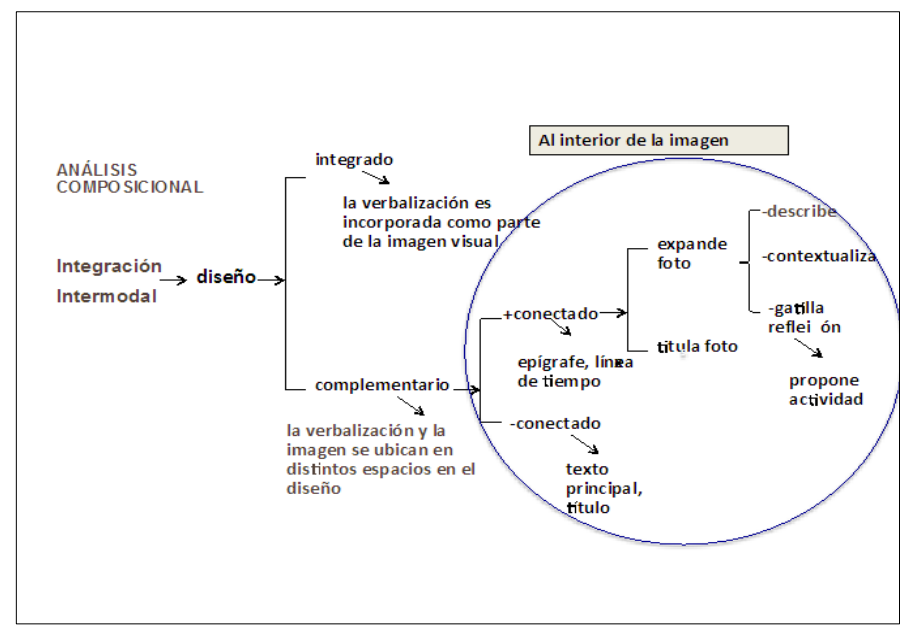

Figura 2. Análisis Composicional de Painter et al. (2013), con adaptación de autores para el análisis de textos escolares de historia.

En la Figura 3 dispuesta a continuación, se presenta la propuesta de Kress y van Leeuwen (2006) para el análisis interactivo con la adaptación de Painter et al. (2013) para el estudio de los libros álbum. 


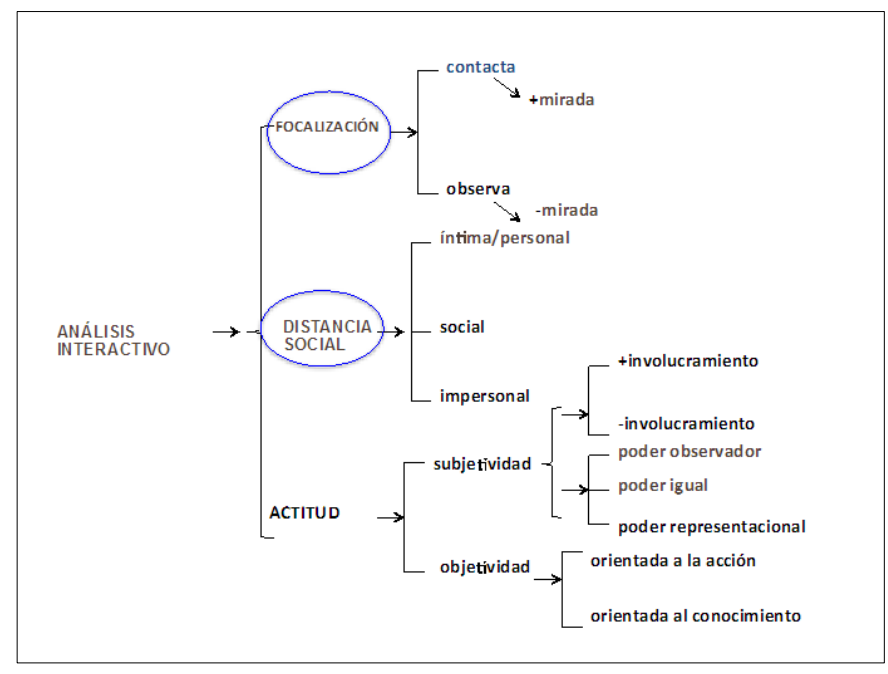

Figura 3. Análisis Interactivo (Kress \& van Leeuwen (2006); adaptación de Painter et al., 2013).

Por su parte, la Figura 4 representa el subsistema de actitud adaptado para el análisis de las imágenes, tal como lo han propuesto Painter et al. (2013). Lo valioso de esta adaptación es su capacidad para trabajar con sistemas semánticos diseñados para cada modo semiótico, pero basados en un mismo paradigma sociosemiótico de construcción de significados en el marco de la lingüística sistémico funcional.

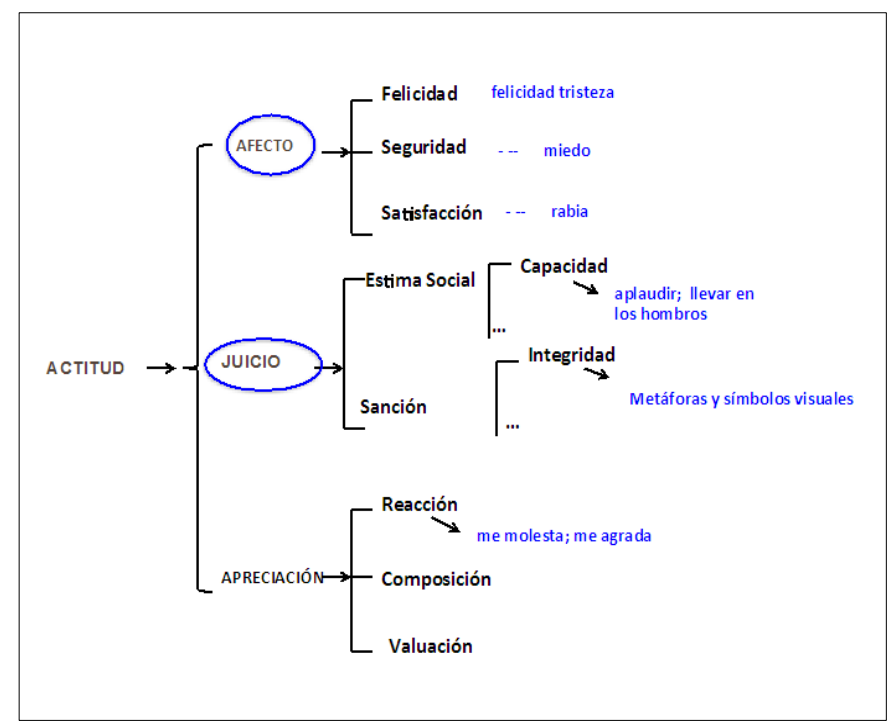

Figura 4. Sistema de ACTITUD de Martin y White (2005). Aplicación a las imágenes adaptado por Economou (2009) y Painter et al. (2013). 
Finalmente, en la Figura 5, mostramos el sistema de APRECIACIÓN elaborado por Oteíza y Pinuer (2012, con algunas modificaciones) para el análisis de eventos y procesos históricos y su adaptación para el análisis visual.

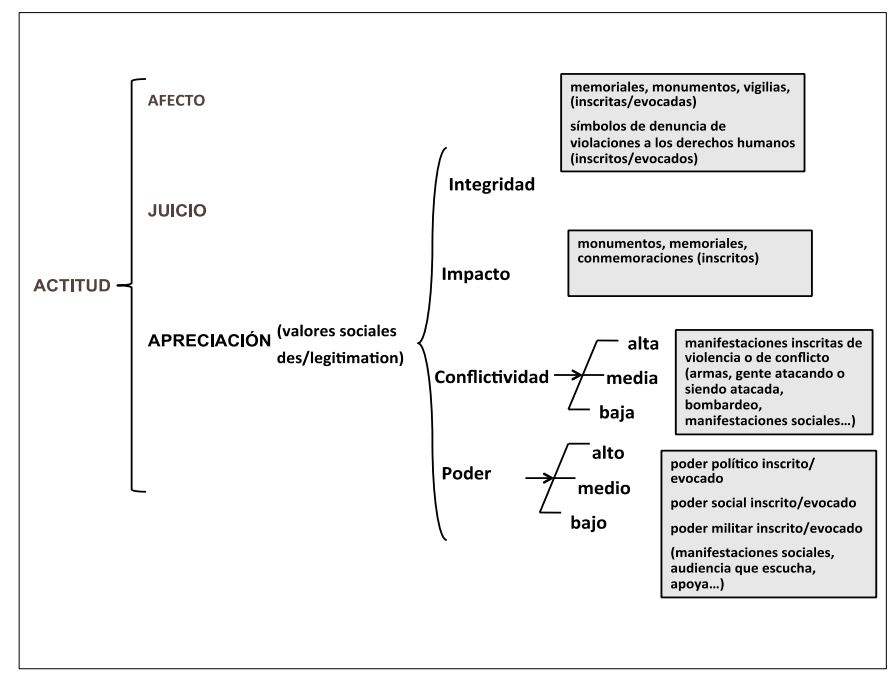

Figura 5. Sistema de apreciación adaptado a imágenes (reformulación de Oteíza \& Pinuer (2012), con modificaciones). ${ }^{2}$

\section{Análisis y discusión}

En esta sección se desarrolla un análisis intermodal de espacios semióticos construidos para representar la violación a los derechos humanos cometidas por la dictadura militar de A. Pinochet (1973-1990) en textos escolares para sexto año de enseñanza básica. ${ }^{3}$ La presentación del análisis y discusión de los resultados se organiza en dos secciones, correspondientes al evento golpe de Estado de 1973, y al proceso histórico de represión política.

En cuanto al análisis del significado ideacional, atenderemos de manera particular los eventos, participantes y circunstancias incluidos en la descripción de la represión política y la violación a los derechos humanos cometidos en dictadura. Para efectos de este artículo y por razones de espacio, nos centraremos únicamente en la presentación de eventos y procesos históricos y dejaremos de lado los actores sociales individuales y colectivos. De esta manera, examinaremos los eventos claves como el bombardeo al palacio presidencial de La Moneda el 11 de septiembre de 1973 y las vigilias y velatones realizadas por familiares de detenidos desaparecidos. En materia de procesos históricos, nos centramos en los acontecimientos de violencia y represión política de estado que han sido objetivados en espacios simbólicos de memoriales, muros y museos. 


\subsection{Evento histórico: Golpe de Estado y bombardeo del Palacio Presidencial de La Moneda el 11 de septiembre de 1973}

Para realizar un análisis intermodal, es prioritario interpretar la imagen en el contexto de la unidad, de las secciones y del cuerpo principal en el que esta aparece. Por lo mismo, si bien el foco del análisis es la construcción intermodal entre imagen y epígrafe añadido, es necesario examinar el modo verbal del cuerpo principal. Así, en el texto escolar de editorial MN publicado en el año 2009 y que se imprime sin modificaciones el año 2012 -al menos las secciones seleccionadas para la presente investigación-, representa el golpe de Estado y el bombardeo de La Moneda de la siguiente manera en el cuerpo principal del texto (Ejemplo 1):

Ejemplo 1: 4

Su incapacidad [de Allende] para controlar los grupos extremistas de izquierda, los


partidos opositores y la secreta intervención de Estados Unidos, crearon un ambiente de desorden general. Los paros, el desabastecimiento, el mercado negro y los violentos enfrentamientos callejeros derivaron en una división y polarización tan profunda que se temía una guerra civil.

En ese escenario, el 11 de septiembre de 1973 los mandos militares dieron un violento golpe de Estado. El Palacio de La Moneda, símbolo de la tradición democrática chilena, fue bombardeado. En su interior y negándose a una rendición, el presidente Allende puso fin a su vida. (Unidad 7: "Visión Panorámica de la Historia de Chile"; sección "La vía chilena al socialismo", Editorial MN 2009/2012).

Como se puede comprobar en el Ejemplo 1, S. Allende es evaluado con un juicio de Estima Social de Capacidad negativa inscrita ("incapacidad", "desaciertos"). Asimismo, la situación política y económica durante su gobienno también recibe una valoración negativa de apreciación con una alta Conflictividad también inscrita, que aparece graduada por Fuerza: "desorden general”, "tan profunda”; así como con una valoración de afecto negativo de Inseguridad inscrita que colabora a representar a una sociedad chilena atemorizada frente a la posibilidad de una guerra civil: "se temía una guerra civil". De este modo, se deslegitima social y políticamente al gobierno de S. Allende. En relación al evento golpe del Estado y bombardeo a La Moneda, se releva el palacio presidencial como un "símbolo de la tradición democrática chilena", por lo que su ataque puede ser considerado, por un lado, con una valoración de apreciación positiva de Valuación e Integridad y, por otro, con una valoración de apreciación negativa de Integridad que deslegitima al evento de violencia.

A continuación, desarrollaremos el análisis de la imagen del bombardeo a La Moneda (Imagen 1), inserta en los textos de MN (2009, 2012) y en el resto de los textos del corpus. Esta imagen es incorporada con un epígrafe al interior de la imagen: "La Moneda en llamas". La fotografía constituye una imagen inscrita de violencia y conflictividad que marca el inicio de la dictadura y la posterior violación a los derechos humanos. En varios de los libros analizados, la imagen del bombardeo al palacio 
presidencial es integrada en la sección de actividades, donde se solicita a los estudiantes indagar sobre la visión de sus padres y familiares respecto a este evento, con la finalidad de que el niño o la niña obtenga sus propias conclusiones luego de poner en común con sus compañeros lo conversado en el hogar. Se apela, por tanto, al testimonio de las generaciones anteriores como estrategia para construir la evidencia (Oteíza, 2014). Como evento, necesariamente se inserta en un proceso mayor, en este caso, la confabulación que incluyó la participación de actores locales, regionales y globales en una conspiración político-militar en Chile para derrocar a un gobierno legítimamente constituido.

Esta imagen simbólica del bombardeo a La Moneda que circuló internacionalmente en la prensa el 11 de septiembre de 1973 y que ha sido publicada sistemáticamente en todos los libros de historia de enseñanza básica y media desde el año 1990, puede considerarse un 'ícono empático' atendidas las conexiones que establece con diferentes memorias emblemáticas (Stern, 2013) que conviven en la sociedad chilena. Por una parte, representa el inicio de la dictadura y la violación a los derechos humanos que se cometieron desde ese día a un sector de la sociedad chilena y simboliza para otro sector de chilenos la salvación del país de una eventual 'dictadura marxista'. La Imagen 1 constituye la única representación visual inscrita de violencia y conflicto del pasado reciente chileno en los textos escolares de historia de primaria.

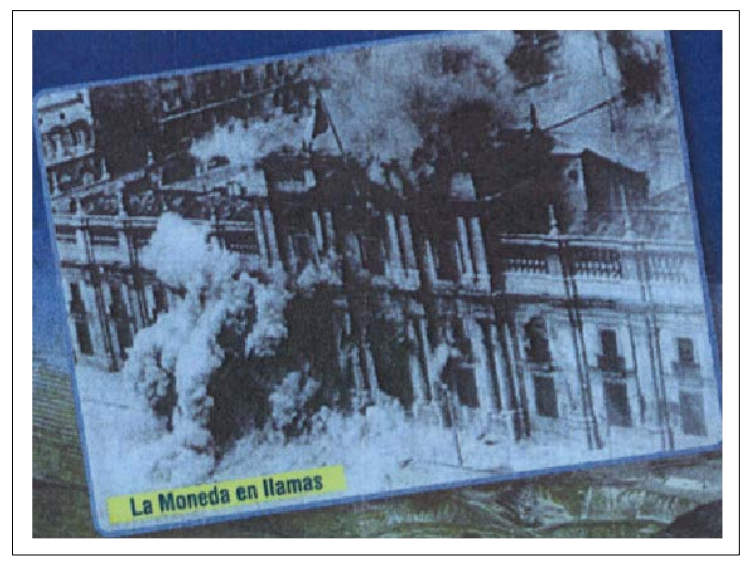

Imagen 1. Evento: Bombardeo de La Moneda el 11 de septiembre de 1973. MN Sexto Básico, 2009; (2012): 175.

Por otra parte, esta imagen corresponde a una narrativa, no ritual y no transactiva (ver Figura 1). El humo y el fuego forman los vectores que permiten identificar que está ocurriendo una acción. La toma es lejana, desde abajo y el ángulo es oblicuo. La subjetividad es baja dado que no se establece contacto con el observador, no hay presencia de seres humanos y la distancia de la fotografía es social. En términos del sistema de valoración, se constata por su interacción con el co-texto visual y verbal 
una evaluación de apreciación negativa, de alta Conflictividad inscrita y de Integridad negativa evocada. Si se considera solo la imagen, puede plantearse que la deslegitimación política, social y ética es evocada, pero desde un punto de vista de la integración intermodal (visual-verbal), esta deslegitimación está inscrita si se toma en cuenta el resto de la unidad en su modo verbal. Esta imagen de "La Moneda en llamas" se incluye al final de la Unidad 7: "Visión Panorámica de la Historia de Chile", y va seguida de actividades para los estudiantes. Asimismo, en el texto de Zig-Zag (2013), la imagen está asociada a actividades de reflexión de los estudiantes, las cuales favorecen la transmisión intergeneracional que mencionáramos previamente y la legitimización de las opiniones personales de la memoria del pasado reciente nacional a través de preguntas como: "¿Qué ideas, mensajes o significados llegan a tu mente al observar una imagen visual o audiovisual del palacio de la Moneda bombardeado?" (Zig-Zag, Sexto básico, 2013: 166). Como sostienen Piper et al. (2013), en Chile, el golpe de Estado de 1973 ha sido y sigue siendo un epicentro de las memorias del pasado reciente.

\subsection{Proceso histórico: La represión durante la dictadura militar}

Para abordar el análisis intermodal del proceso de represión durante el régimen militar, tomamos en cuenta el significado a nivel verbal y visual. Como se indicó en la sección 2.1., es fundamental considerar la totalidad de la página en la que se insertan las imágenes y contextualizarlas en el marco de la sección y de la unidad de la que forman parte. Hemos detectado en análisis anteriores (Oteíza, 2014) que en las explicaciones históricas de los manuales escolares se establece una fuerte intertextualidad con el Informe Rettig (1991) y se construye un discurso que:

"privilegia la presentación de un país polarizado y que experimenta una situación de violencia generalizada", así como que "toda la sociedad chilena es la responsable por esta crisis y violencia” (Oteíza, 2014: 22).

En la Imagen 2 se puede observar la página del texto de Arrayán 2005-2006 que revisa este capítulo de la historia de la represión política nacional: 


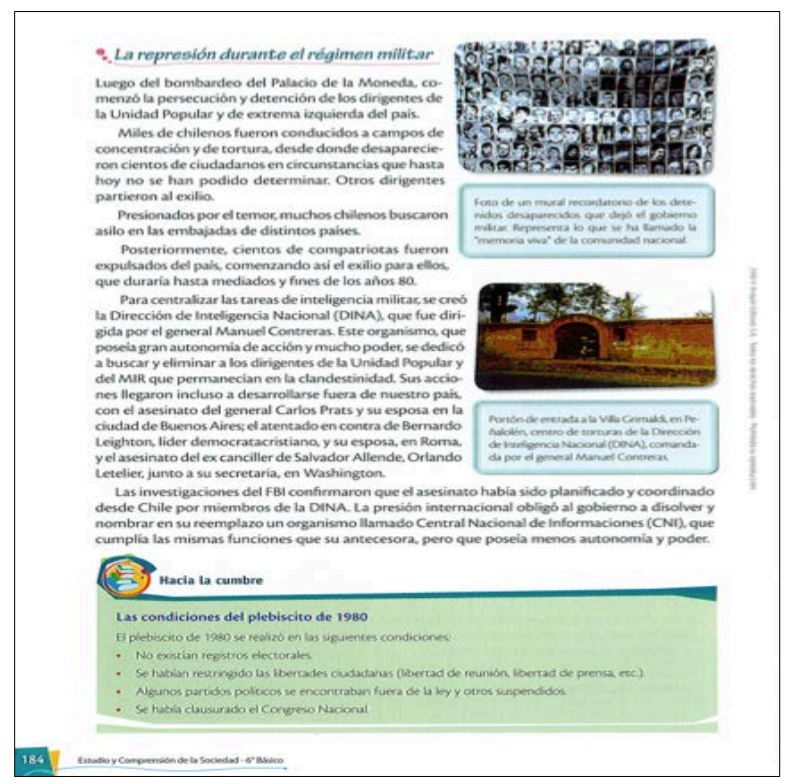

Imagen 2. Página del texto escolar que trata sobre la 'represión durante el régimen militar’. Arrayán, Sexto Básico, 2005-2006: 184.

La relación intermodal se produce composicionalmente a varios niveles: imágenes/ título/ cuerpo principal, imágenes/imágenes e imagen/epígrafe (unidad 'fotografía+ epígrafe'). A continuación, nos centraremos en la relación que cada imagen establece con su epígrafe, pues se observa entre ambos una integración intermodal fundamental y primaria para la lectura de las imágenes.

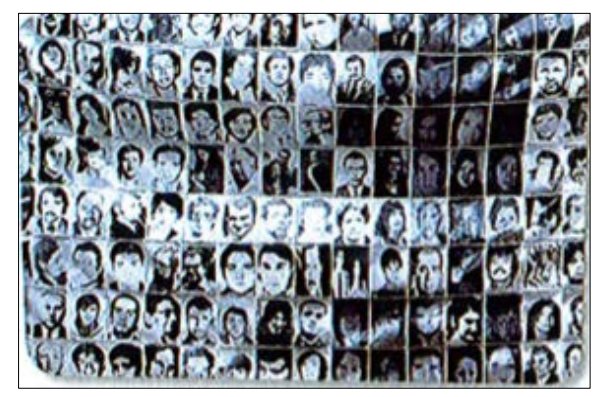

Foto de un mural recordatorio de los detenidos desaparecidos que dejó el gobierno militar. Representa lo que se ha llamado la "memoria viva" de la comunidad nacional.

Imagen 3. Fotografía + epígrafe. Arrayán, Sexto Básico, 2005-2006: 184.

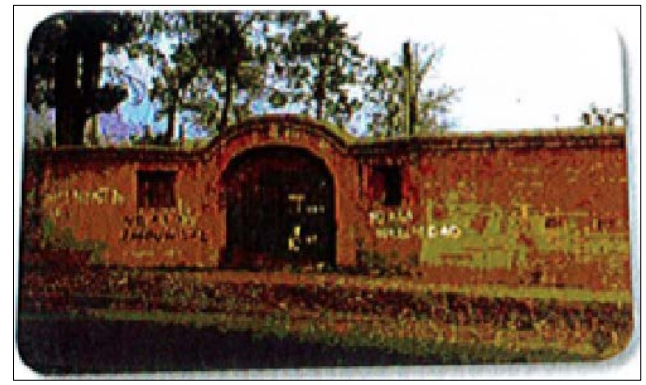

Portón de entrada a la Villa Grimaldi, en Peñalolén, centro de torturas de la Dirección de Inteligencia Nacional (DINA), comandada por el general Manuel Contreras.

Imagen 4. Fotografía + epígrafe. Arrayán, Sexto Básico, 2005-2006: 184.

La Imagen 3 constituye una imagen conceptual simbólica, no ritual y funciona como un ícono empático de denuncia. Como proceso relacional atributivo presenta los rostros de las víctimas de la represión (detenidos desaparecidos), los cuales están 
asociados a valores simbólicos de una manera convencional, como la violencia y la reparación, ampliamente difundidos en nuestro país y otros países latinoamericanos. Las filas no construyen una jerarquía, dado que todos los rostros tienen el mismo valor y no se visualizan como un muro. Es una imagen simbólica y, por sí misma, inscribe una valoración de sanción ética hacia quienes cometieron violaciones a los derechos humanos durante la dictadura militar. Es una imagen que establece una relación de 'observa' (ver Figura 3), con una distancia personal/social y que posee una mediana subjetividad, ya que hay presencia de seres humanos, pero debido a la distancia de los rostros el involucramiento es mediano. En relación con la violencia cometida en contra de las personas representadas, se aprecia en la imagen una valoración de apreciación negativa de Integridad que deslegitima éticamente esta violencia de manera evocada.

En el epígrafe que acompaña la Imagen 3, son evaluados, por una parte, el gobierno militar con un juicio evocado de Sanción Social negativa de Integridad ("dejó"), ya que se representa como un legado del gobierno militar. La sociedad que recuerda es codificada a través de un proceso verbal impersonal "lo que se ha llamado", que remite a la memoria emblemática de la sociedad chilena. Esta es evaluada con una apreciación positiva de Impacto y de Integridad, por lo que se la legitima social y éticamente de forma evocada. En la integración intermodal 'fotografía+epígrafe', se observa una composición complementaria y conectada, en donde el epígrafe expande la foto, dado que la describe y contextualiza (ver Figura 2).

En la Imagen 4, se presenta la segunda foto de la página del texto escolar analizado.

Esta fotografía corresponde a una imagen conceptual simbólica y no ritual. Solo se muestra un muro y un portón, elementos suficientes para representar un lugar. Desde un punto de vista interactivo, no establece una conexión de involucramiento con el observador dada su distancia social, la ausencia de seres humanos y de acción. El muro y portón (representación de un lugar de violación a los D.D.H.H. y tortura) son evaluados con una APRECIACIÓN negativa de Integridad que deslegitima éticamente la violación a los derechos humanos en un extremo máximo de evocación. Lo críptico y poco comunicativo de un muro no permite recuperar visualmente el significado simbólico respecto a su valor en relación a la represión política, sino a través del modo verbal. Por oposición, en el epígrafe se evalúa a la DINA con un juicio inscrito negativo de Sanción Social de Integridad ("torturas"). El General Manuel Contreras también es valorado con un juicio negativo de Sanción Social de Integridad evocada, en su papel de director del centro de torturas. Asimismo, lo que ocurrió en el lugar (Villa Grimaldi) se valora con una apreciación negativa de Integridad que deslegitima ética y socialmente de manera inscrita los delitos allí cometidos ("torturas"). Si consideramos la integración intermodal, es posible afirmar que el epígrafe expande la imagen, pues la describe y contextualiza permitiendo el 
establecimiento de la Sanción Social moral que sería imposible obtener sólo de la fotografía. Así, la evaluación ética solo se produce de manera inscrita a nivel intermodal. Esta fotografía del portón de entrada a la Villa Grimaldi representa la evidencia de un proceso y del resultado de la lucha por perpetuar la memoria de las víctimas (acciones contra el olvido), particularmente por parte de las organizaciones de derechos humanos y de familiares y amigos de detenidos desaparecidos y secundariamente por organismos gubernamentales. Como sostiene el Informe de Naciones Unidas del año 2013:

"El creciente número de construcción y mantención de memoriales tendientes a la preservación de la memoria histórica ha sido el producto de iniciativas de la sociedad civil, principalmente de las organizaciones de familiares de víctimas y no de una política cuya iniciativa radique en el Estado" (Informe de Naciones Unidas, 2013: 13).

La Imagen 5 que analizamos a continuación inicia la sección de "Dictadura y neoliberalismo: 1973-1990" de un libro más reciente publicado por Editorial Marenostrum en 2009:

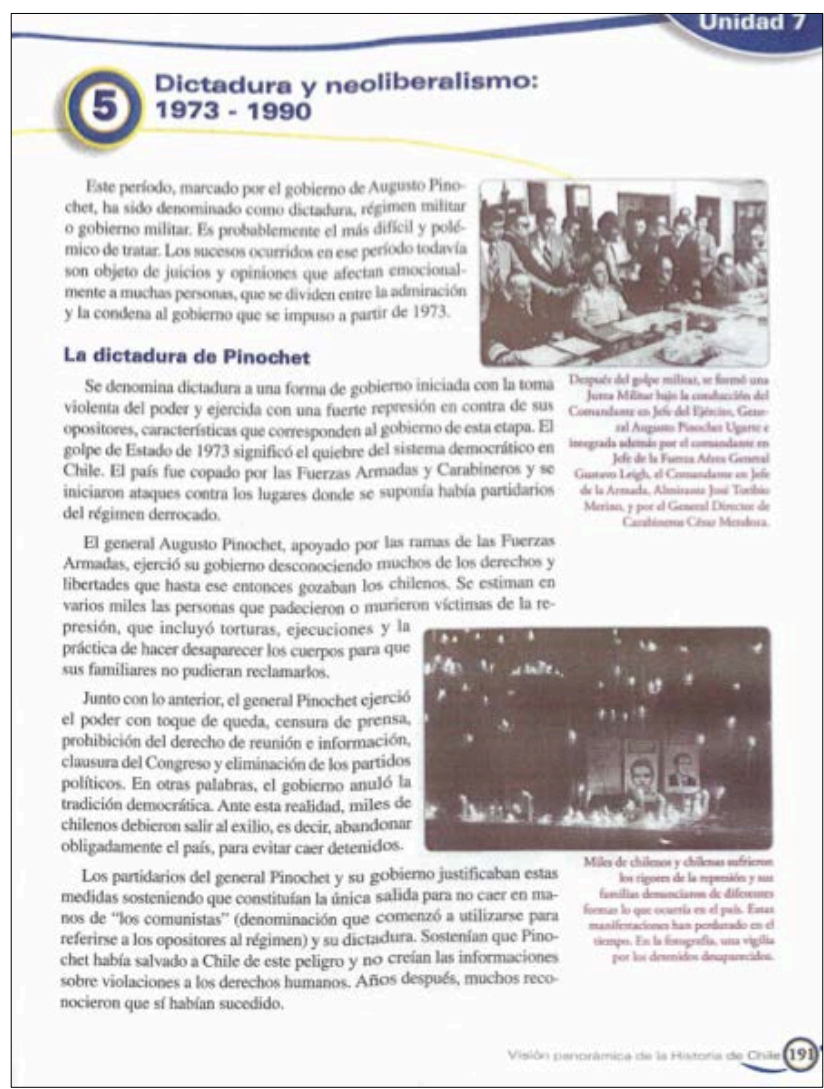

Imagen 5. Página del texto escolar que trata sobre 'Dictadura y neoliberalismo: 1973- 1990'. Marenostrum, Sexto Básico, 2009: 191. 


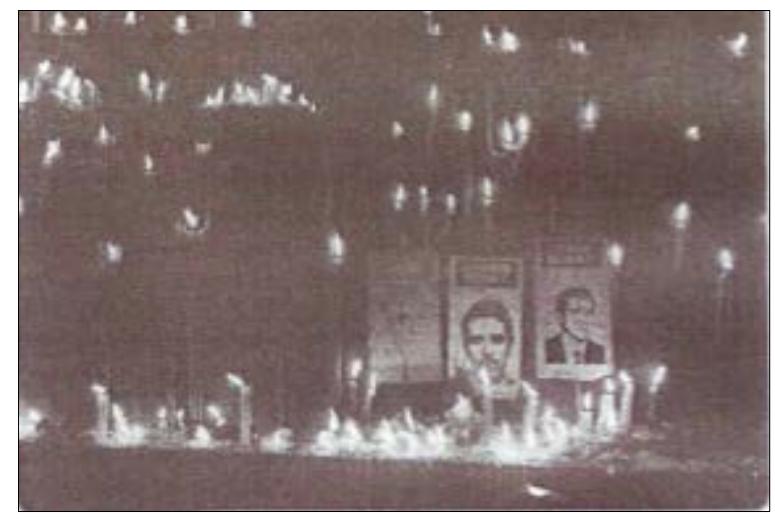

Miles de chilenos y chilenas sufrieron los rigores de la represión y sus familias denunciaron de diferentes formas 10 que ocurría en el país. Estas manifestaciones han perdurado en el tiempo. En la fotografía, una vigilia por los detenidos desaparecidos.

Imagen 6. Marenostrum, Sexto Básico, 2009: 191. (Reproducida de manera idéntica en el año 2012).

En consonancia con el foco del análisis (violación a los derechos humanos), examinaremos en detalle solo la segunda fotografía de la página (Imagen 6), comenzando por destacar que representacional y composicionalmente es relevante que se ubique bajo una fotografía de la Junta Militar. La Imagen 6 es una imagen conceptual, simbólica, ritual- en cuanto representa el accionar de memorias colectivas e incorpora íconos empáticos de denuncia (fotografías de detenidos desaparecidos con el lema “¿Dónde están?”). El foco está puesto en el ritual de la vigilia y de la velatón, expresado por el simbolismo de las velas encendidas y de los afiches con los rostros de las personas desaparecidas ('íconos empáticos'). La distancia establecida con el observador es social y, por lo mismo, no se logra un contacto de mirada con el lector. La imagen es medianamente subjetiva pues, si bien incluye seres humanos, no hay acción y su distancia produce un involucramiento mediano. La violación a los D.D.H.H. de las víctimas de las fotografías incluidas en el rito de la vigilia es evaluada con una apreciación negativa de Integridad que deslegitima éticamente este traumático capítulo de la historia nacional.

En el epígrafe se presenta un discurso de denuncia por parte de los familiares y de victimización de quienes sufrieron la represión, sin asignar responsabilidades. Los "rigores de la represión" y "lo que ocurría", en cuanto procesos históricos, se evalúan con una apreciación negativa de alta Conflictividad e Integridad negativa inscrita y evocada, que conlleva una deslegitimación ética y social. Los "Miles de chilenos y chilenas" son valorados con un afecto negativo de Inseguridad inscrito que está graduado por Fuerza: "miles". Los familiares (nominalizados en "estas manifestaciones") son evaluados con un juicio positivo de Sanción Social y de Estima Social de Integridad y Tenacidad, inscrito y también graduado por Fuerza de extensión 
temporal: "han perdurado en el tiempo". Una lectura intermodal permite captar una valoración inscrita de deslegitimación ética.

Finalizaremos el análisis, examinando una página del texto más reciente del corpus (Zig-Zag, 2013), la cual incluye un macro epígrafe que precede a cuatro fotografías acompañadas de un epígrafe distintivo. El análisis estará centrado en las primeras dos imágenes y sus respectivos epígrafes. Por razones de espacio las imágenes restantes serán consideradas de forma complementaria.



Parque por la Paz Villa Grimaldi”, lugar que fue un campo de detención y tortura durante el régimen militar. En la imagen la lista de las personas que pasaron por el lugar.

\section{Imagen 7. Fotografía + epígrafe. Zig-Zag,} Sexto Básico, 2013: 177.

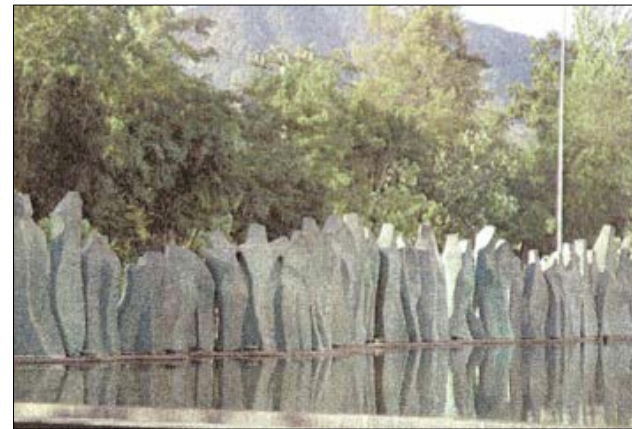

Memorial al Senador Jaime Guzmán, asesinado en 1991 por un grupo de extrema izquierda. A través de él se busca perpetuar su pensamiento.

Imagen 8. Fotografía + epígrafe. Zig-Zag, Sexto Básico, 2013: 177.

Esta imagen es interpretable como una narrativa, no ritual, transaccional, reaccional y mental. Puede observarse un grupo de personas, de espaldas, que observan el muro de conmemoración de Villa Grimaldi mientras un guía les habla del lugar. La imagen presenta una distancia social y una subjetividad media, dado que los seres humanos no establecen un contacto con el observador, la acción es apenas perceptible y el involucramiento es, por tanto, bajo. Las violaciones a los D.D.H.H. representadas en el Muro de Villa Grimaldi (símbolo de la represión política y de la tortura) son valoradas con una apreciación negativa de Integridad que deslegitima éticamente estas prácticas, de manera evocada en grado máximo.

El epígrafe que acompaña a esta Imagen está construido con énfasis en la circunstancia temporal-espacial (Fuerza): es el lugar que fue centro de detención y tortura durante el régimen militar, incluyendo una "lista de las personas que pasaron por el lugar". Las violaciones a los DDHH representadas desde la circunstancia temporal y espacial, son valoradas con una apreciación negativa de Integridad que las deslegitima ética y socialmente de manera evocada. "La lista de las personas que pasaron por el lugar" es evaluada con un afecto negativo de Inseguridad que 
manifiesta de manera altamente evocada el sufrimiento de las víctimas, ya que no se dice explícitamente que fueron torturadas sino que 'pasaron por el lugar'. Desde una lectura intermodal, imagen y epígrafe son complementarias, están conectados, y el epígrafe expande la fotografía en cuanto la describe y contextualiza con énfasis en las circunstancias temporales y espaciales.

Por último, la Imagen 9 del Memorial al Senador Jaime Guzmán se ubica en la posición de máxima visibilidad (cuadrante izquierdo-superior) de acuerdo con el nivel de prominencia de la página. Esta fotografía corresponde a una imagen conceptual, no ritual y simbólica. En ella es posible ver un monumento conformado por columnas de piedra irregulares situadas junto a una laguna. Al no existir presencia humana, esta fotografía es de mayor abstracción que el muro de Villa Grimaldi (Imagen 8). Se presenta con bajo involucramiento respecto del observador, no es posible establecer un contacto con la mirada y no hay acción. Por lo mismo, y dada la distancia social de la toma, es una foto que tiende a la objetividad. En la imagen, la violación a los DDHH, plasmada a través del Memorial al Senador Jaime Guzmán, es evaluada con una apreciación negativa de Integridad que deslegitima éticamente esta acción con un alto nivel de evocación. En este texto escolar se equipara composicionalmente a las víctimas de la dictadura (más de 39.000 en cifras generales) con el asesinato de Jaime Guzmán. De esta forma, las víctimas de la derecha y las víctimas de la izquierda simbolizan un clima de "violencia generalizada" o de "violencia política" en el período que, como se menciona en el macro epígrafe, es lo que debe recordarse como un "imperativo ético" de la sociedad.

En el epígrafe se individualiza a un grupo social como responsable del asesinato y, por ello; un grupo de extrema izquierda es evaluado con un juicio negativo de Sanción Social de Integridad inscrita (“asesinado en 1991 por..."). Este es el único discurso que no se centra en la conmemoración de las víctimas, sino que expresa una valoración del pensamiento del Senador Jaime Guzmán- ideólogo de la dictadura y de la Constitución de 1980- con el agregado de que el memorial "busca perpetuar su pensamiento"; así, Guzmán es valorado con un juicio positivo de Estima Social de Capacidad. Desde un análisis de integración intermodal, se puede establecer que el epígrafe es complementario y conectado con la foto como expansión, ya que describe y contextualiza la imagen, permitiendo inscribir una valoración del Senador Guzmán y del grupo de extrema izquierda que no podría captarse solo con la imagen. Tanto en la Imagen 8 como en la Imagen 9, los actores sociales son incorporados únicamente en el modo verbal.

La página del texto de Zig-Zag corresponde al término de la Unidad 4 sobre desarrollo y democratización. En esta sección se aprecia un recuento estadístico de las víctimas sin que medie una explicación de la significación histórica de las brutales cifras. La información se presenta en términos impersonales e indeterminados en 
tercera personal plural, con procesos existenciales y con una agencia selectiva de los responsables de la violencia (Oteíza, 2014).

En la Figura 6 se presenta de manera sintética las relaciones de intertextualidad y de construcción de la evidencia en textos escolares de historia para sexto básico publicados entre el año 2005 y 2013 en Chile, desde una perspectiva intermodal.

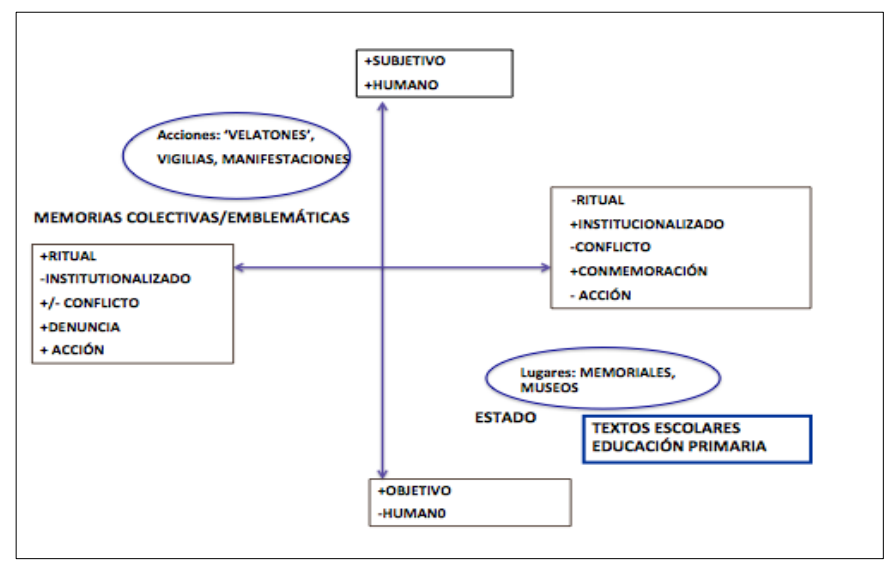

Figura 6. Intertextualidad y construcción de la evidencia intermodal en el discurso de la historia escolar de enseñanza básica sobre la violación a los derechos humanos.

\section{CONCLUSIONES}

$\mathrm{El}$ análisis nos indica que la evidencialidad descansa en ambos modos y con un rol especial del sistema de gradación como Fuerza en el modo verbal (intensificación, cantidad y extensión temporal). Los epígrafes enfatizan la continuidad temporal y la vigencia del conflicto social en la sociedad chilena: "hasta el día de hoy"; "memoria viva"; "han perdurado en el tiempo". Los epígrafes cumplen un rol fundamental en la construcción de prosodias valorativas intermodales a través de recursos de descripción, contextualización y como gatilladores de reflexión mediante las actividades sugeridas.

Los espacios semióticos verbales y visuales interactúan generando una distancia social y una representación más orientada hacia el conocimiento, con baja presencia de actores humanos. Las fotografías conceptuales y narrativas de memoriales, vigilias, edificios de gobierno y museos de la memoria funcionan como fuentes primarias que co-construyen un discurso objetivado y medianamente ritualizado. Se elimina el conflicto y la violencia y se privilegian los ritos de denuncia y de reparación social, lo que resulta concordante con las estrategias de despolitización de la memoria traumática del país. Las valoraciones de Sanción Social de Integridad o de valoración negativa de Conflictividad, con la consecuente deslegitimación política y ética, son evocadas en el modo visual y solo pueden considerarse inscritas desde una lectura 
intermodal. Sin embargo, puede plantearse de manera preliminar que los íconos empáticos de denuncia inscriben una sanción social de integridad negativa, sin que sea necesario una lectura intermodal con el texto escrito.

Las nociones de legitimación y deslegitimación histórica se plasman como valoraciones de carácter más global que se nutren de varias categorías las cuales, en combinación, construyen una y otra noción en el discurso de la historia. Las legitimaciones se inscriben en el discurso, según van Leeuwen (2008), como una manera de explicar por qué existen determinadas prácticas sociales y por qué toman la forma que toman. Las legitimaciones y deslegitimaciones se construyen intermodalmente, en parte, a través de la evidencia en los textos escolares de historia. Así, las imágenes de los memoriales y de los museos funcionan como evidencia objetivada de procesos sociales y políticos. Estos procesos son respaldados con diversos grados de explicitud en la autoridad de los informes oficiales (Rettig y Valech), como documentos oficiales que han fundamentado mediante la recolección de testimonios, la violación a los derechos humanos y la existencia de lugares de detención y tortura. La legitimación se muestra, principalmente, de manera intermodal por la acción de grupos sociales que defienden memorias emblemáticas y, en menor grado, desde el accionar del Estado. Se igualan los dolores y se relativiza el pasado reciente. El memorial del senador de derecha e ideólogo de la dictadura se ubica junto al memorial de las casi 40.000 víctimas del terrorismo de Estado de la dictadura de Pinochet (Texto escolar Zig-Zag, 2013). Se evita el conflicto, se hace un esfuerzo por convivir con las diferencias sobre las memorias del pasado reciente (Reyes, Muñoz \& Vázquez, 2013). En palabras de Lira (2013: 11) ocurre una "cancelación de la memoria del conflicto" y se vive "una impunidad compartida" como fundamento de la paz social y de la reconciliación.

A diferencia de lo identificado en otros estudios dedicados exclusivamente al análisis de la dimensión verbal, la consideración intermodal (visual-verbal) nos permite demostrar que en estos textos no solo se presenta "un discurso de denuncia y de victimización que se basa en la evidencia recogida en los informes oficiales sobre violación a los derechos humanos Rettig (1991) y Valech (2004) y Valech (2011)" (Oteíza, 2014: 130), sino que se destaca el rol clave desempeñado por los organismos de defensa de los derechos humanos como la Agrupación de Familiares de Detenidos Desaparecidos y otros actores no identificados que recuperan la 'conmemoración' y el 'recuerdo' como parte de la transmisión de las memorias del pasado reciente a las nuevas generaciones de niños y niñas.

La memoria se objetiva en espacios, los eventos como el bombardeo a La Moneda se hacen protagonistas y se remueve a los actores. Los memoriales como espacios físicos de enunciación de la memoria favorecen la reconciliación y la despolitización de la memoria histórica de país. Los íconos empáticos conectan especialmente con valores compartidos de denuncia y de contramemorias. No es posible ver la 
manifestación visual de la violación a los derechos humanos, tampoco a sus responsables -solo a la Junta Militar de manera indirecta por el diseño composicional de la página. El proceso sistemático de terrorismo de Estado permanece en los lugares en que se practicó, la dictadura de Pinochet es circunstancializada en un periodo, y de las víctimas tenemos sus rostros distantes y grabados en las paredes de monumentos y afiches conmemorativos. En cuanto a la violación a los derechos humanos, los manuales incorporan cifras y nominalizaciones que señalan la brutalidad de la dictadura, pero no se visualiza el proceso, solo sus consecuencias en un discurso de victimización, conmemoración y denuncia que no conduce a la reflexión histórica. De este modo, estos textos estarían escasamente alineados con la convocatoria realizada en Chile durante la conmemoración de los 40 años del golpe militar en el año 2013, en la que se hicieron llamados desde diferentes sectores de la sociedad a "desplazar el foco del recuerdo desde las víctimas hacia la recuperación de las experiencias históricas y proyectos transformadores, con el fin de contribuir a las luchas del presente" (Piper et al., 2013: 28). 


\section{REFERENCIAS BIBLIOGRÁFICAS}

Achugar, H. (2003). El lugar de la memoria, a propósito de monumentos (Motivos y paréntesis). En E. Jelin \& V. Langland (Comps.), Monumentos, memoriales y marcas territoriales (pp. 191-214). Madrid: Siglo Veintiuno.

Achugar, M. (2008). What we remember. The construction of memory in military discourse. Amsterdam: John Benjamins.

Achugar, M., Fernández, A. \& Morales, N. (2014). La dictadura uruguaya en la cultura popular: Recontextualización de "A redoblar". Discurso \& Sociedad, 8(1), 83108.

Augustowsky, G., Massarini, A. \& Tabakman, S. (2011). Enseñar imágenes en la escuela. Buenos Aires: Tinta Fresca Ediciones S.A.

Bernstein, B. (2000). Pedagogy, symbolic control and identity. Theory, research, critique. Lanhan, Boulder, New York, Oxford: Rowman \& Littlefield Publishers.

Borges, A. (2011). Representações no discurso da história: A relação imagen-textoideologia. Discurso \& Sociedad, 5(4), 628-644.

Derewianka, B. \& Coffin, C. (2008). The visuals in history textbooks: Some pedagogic issues. En L. Unsworth (Ed.), Multimodal Semiotics: Functional Analysis in Contexts of Education (pp. 187-200). Londres: Continuum.

Economou, D. (2009). Photos in the news: Appraisal of visual semiosis and visual verbal intersemiosis. Tesis doctoral, Universidad de Sydney, Sydney, Australia.

Jelin, E. (2002). Los trabajos de la memoria. Madrid: Siglo Veintiuno.

Jelin, E. (2007). La conflictiva y nunca acabada mirada sobre el pasado. En M. Franco \& F. Levín (Comp.), Historia reciente. Perspectivas y desafios para un campo en construcción (pp. 307-340). Buenos Aires/Barcelona: Paidós.

Jelin, E. \& Langland, V. (2003). Introducción. Las marcas territoriales como nexo entre pasado y presente. En E. Jelin \& V. Langland (Comps.), Monumentos, memoriales y marcas territoriales (pp. 1-18). Madrid: Siglo Veintiuno.

Kress, G. \& Van Leeuwen, T. (2006). Reading images. The grammar of visual design. Londres/Nueva York: Routledge.

Lechner, N. (2006). Las sombras del mañana. La dimensión subjetiva de la política. Santiago de Chile: LOM.

Lira, E. (2013). Algunas reflexiones a Propósito de los 40 años del Golpe Militar en Chile y las Condiciones de la Reconciliación Política. Psykhe, 22(2), 5-18. 
Manghi, D. (2013a). Representación y comunicación del conocimiento en Educación Media: Análisis multimodal del discurso de materiales utilizados para la enseñanza escolar de la historia y de la biología. Onomázein, 27, 25-52.

Manghi, D. (2013b). Géneros en la enseñanza escolar: Configuraciones de significado en clases de historia y biología desde una perspectiva multimodal. Revista Signos. Estudios de Lingüistia, 82(46), 236-247.

Manghi, D. \& Badillo, C. (2015). Modos semióticos en el discurso pedagógico de historia: Potencial semiótico para la mediación en el aula escolar. Íkala, 20(2), 157-172.

Martin, J. R. (2008). Intermodal reconciliation: Mates in arms. En L. Unsworth (Ed.), New Literacies and the English Curriculum (pp. 112-148). Londres/Nueva York: Continuum.

Martin, J. R. \& White, P. (2005). The language of evaluation. Appraisal in English. Nueva York: Palgrave Macmillan.

Morales, O. \& Lischinky, A. (2008). Discriminación a través de las ilustraciones de libros de texto de Educación Secundaria obligatoria en España. Discurso \& Sociedad, 2(1), 115-152.

Nora, P. (1989). Between memory and History: Les lieux de Momoire. Representations, 26, 7 24.

Oteíza, T. (2006). El discurso pedagógico de la historia. Un análisis lingüistico sobre la construcción ideológica de la historia de Chile (1970-2001). Santiago, Chile: Frasis.

Oteíza, T. (2009). Diálogo entre textos e imágenes: Análisis multimodal de textos escolares desde una perspectiva intertextual. Delta, Número especial, 25, 664677.

Oteíza, T. (2011). Representación de las memorias del pasado: Intersubjetividad en el discurso pedagógico de la historia. En T. Oteíza \& D. Pinto (Eds.), En (re)construcción: Discurso, identidad y nación en los manuales escolares de bistoria y de ciencias sociales (pp.129-172). Santiago: Cuarto Propio.

Oteíza, T. (2014). Intertextualidad en la recontextualización pedagógica del pasado reciente chileno. Discurso \& Sociedad, 8(1), 109-136.

Oteíza, T. \& Pinuer, C. (2012). Prosodia valorativa: Construcción de eventos y procesos en el discurso de la historia. Discurso \& Sociedad, 6(2), 418-446.

Oteíza, T. \& Pinuer, C. (2013). Valorative prosody and the symbolic construction of time in historical recent national discourses. Discourse Studies, 15(1), 43-64. 
Painter, C., Martin, J. R. \& Unsworth, L. (2013). Reading visual narratives. Image analysis of children's picture books. Lancaster/Bristol: Equinox.

Piper, I., Fernández-Droguett, R. \& Iñiguez-Rueda, L. (2013) Psicología social de la memoria: Epacios y políticas del recuerdo. Psykhe, 22(2), 19-31.

Reyes, M. J., Muñoz, J. \& Vázquez, F. (2013). Políticas de memoria desde los discursos cotidianos: La despolitización del pasado reciente en el Chile actual. Psykhe, 22(2), 161-173.

Ricoeur, P. (2010). Memoria, historia y olvido. México: Fondo de Cultura Económica.

Stern, S. (2013). Luchando por mentes y corazones. Las batallas de la memoria en el Chile de Pinochet. Santiago: Ediciones Universidad Diego Portales.

Van Leeuwen, T. (2008). Discourse and practice. New tools for critical discourse Analysis. Oxford: Oxford University Press.

Wertsch, J. (2002). Voices of collective remembering. Cambridge: Cambridge University Press.

Wodak, R. (2011). La historia en construcción/La construcción de la historia. La "Wehrmacht alemana" en los recuerdos colectivos e individuales de Austria. Discurso \& Sociedad, 5(1), 160-195.

Zullo, J. (2014). El golpe de Estado llega al aula. Las versiones para niños de la historia reciente. Discurso \& Sociedad, 8(1), 12-36.

\section{NOTAS}

1 Debido a limitaciones de espacio, hemos decidido presentar las redes sistémicas de las categorías consideradas en el análisis con el objeto de entregar una presentación sintética de esta teoría. Una explicación detallada de cada categoría puede encontrase en los trabajos de los autores citados.

${ }^{2}$ Por razones de espacio, ver Oteíza y Pinuer $(2012,2013)$ para una definición de las categorías.

${ }^{3}$ De acuerdo con el currículo de historia para la enseñanza básica del Ministerio de Educación, la historia de Chile se aborda en sexto año de Enseñanza Básica.

4 En los ejemplos las valoraciones de actitud inscrita (explícitas) de AFECTO, JUICIO y APRECIACIÓN están señaladas con negrita y subrayado, las evocadas (implícitas) con negrita en cursiva. Las gradaciones de estas valoraciones solo se anuncian con subrayado (ya sea que correspondan a gradaciones de Foco o de Fuerza). 